\title{
O PARADOXO DE CHALMERS
}

Gustavo LEAL-TOLEDO ${ }^{1}$

- RESUMO: O Argumento dos Zumbis proposto por Chalmers, ao contrário de defender o dualismo, bane as qualia para um "mundo" onde elas não podem influenciar o julgamento que fazemos sobre nós mesmos. Por este motivo, pelo próprio argumento, podemos ser um zumbi e não saber. A isso Chalmers chamou de The Paradox of Phenomenal Judgment. O problema é que ele aceita tal paradoxo como parte de sua própria teoria. No entanto, este movimento filosófico não é aceitável e este paradoxo mina a teoria de Chalmers por dentro mostrando que o argumento dos zumbis é, na verdade, um argumento contra o dualismo. Chalmers tenta resolver este problema com uma série de argumentos que tem como base o fato de que a consciência é um bruto explanandum indubitável. No entanto, tal tentativa fracassa por uma série de razões que mostram que mesmo se ele estivesse correto, ainda poderíamos ser um zumbi e não saber.

- PALAVRAS-CHAVE: David Chalmers, Daniel Dennett, Zumbis, Qualia, Dualismo.

Em um artigo anterior, baseado em minha dissertação de mestrado, intitulado Dualism and the Zombie Argument in $20^{\text {th }}$ Century Philosophy of Mind, ${ }^{2}$ eu e o professor João de Fernandes Teixeira levantamos algumas críticas ao argumento dos zumbis proposto por David Chalmers em seu livro

1 Doutor pela Pontifícia Universidade Católica do Rio de Janeiro (PUC-Rio) e Professor adjunto do Departamento de Filosofia da Universidade Federal de São João del Rei. Artigo recebido em 07/2009 e aprovado em 11/2009.

2 Cf. LEAL-TOLeDO, G. \& TEIXEIRA, J. de F. Dualism and the Zombie Argument in $20^{\text {th }}$ Century Philosophy of Mind. In: Análise, II, 2, 2005, pp. 35-52; Cf. LEAL-TOLEDO, G. O Argumento dos Zumbis na Filosofia da Mente: são zumbis físicos logicamente possíveis? 2005. Dissertação (Mestrado em Filosofia) - Departamento de Filosofia, Pontifícia Universidade Católica do Rio de Janeiro, Rio de Janeiro, 2005. 
de 1996, The Conscious Mind. ${ }^{3}$ Neste livro, Chalmers defende que se for logicamente possível pensar em um mundo fisicamente idêntico ao nosso, mas sem consciência, então a consciência não é física. Assim, o simples fato de tal mundo ser concebível nos provaria que a consciência não pode ser reduzida ao seu substrato físico, pois não advém logicamente deste. Tal mundo seria em tudo fisicamente idêntico ao nosso, mas os seres deste mundo não teriam consciência, seriam os chamados zumbis. $\mathrm{O}$ argumento dos zumbis seria, então, que se zumbis são concebíveis a consciência ${ }^{4}$ não é física.

Levantamos contra tal argumento, no artigo citado, várias críticas divididas em dois grandes grupos: o primeiro tenta mostrar que se zumbis são possíveis não podemos saber se somos zumbis ou não; e o segundo tenta mostrar que se não podemos ter acesso as qualia dos outros, não podemos imaginar um ser com qualia para, depois, retira-las. O segundo grupo não será tratado aqui, embora ainda considere tais críticas pertinentes, principalmente por levantarem um ponto também levantado por Dennett, a saber, o fato de que tacitamente já pressupomos as qualia de uma maneira coletiva e pública. ${ }^{5}$ Já algumas das críticas tratadas no primeiro grupo serão muito brevemente apresentadas aqui para auxiliar na compreensão dos argumentos que se seguem.

A linha geral do primeiro grupo de críticas é o fato de que a estrutura e o funcionamento do nosso mundo e do mundo zumbi são idênticos, deste modo, todo o nosso comportamento é explicado fisicamente, mesmo o nosso comportamento que se refere ao nosso julgamento sobre a consciência. Isto significa que zumbis, assim como nós, julgam ser conscientes, e o julgamento deles é causado exatamente pelo mesmo processo físico que causa o nosso. Já que zumbis julgam que são conscientes e não são, como posso saber que o meu julgamento sobre a minha consciência também não está errado, eu posso ser um zumbi e não saber. Outros filósofos já defenderam argumentos com esta mesma linha geral, entre eles podemos citar Shoemaker, Kirk e Guzeldere. ${ }^{6}$ Todos os que defenderam argumentos parecidos

3 CHALMERS, D.H. The Conscious Mind. Oxford: Oxford University Press, 1996.

4 Consciência e qualia serão consideradas sinônimos no decorrer deste artigo. Este uso dos dois termos é comum, no entanto é possível fazer uma diferenciação entre eles que não nos interessa no momento.

5 Cf. DENNETT, Sweet Dreams. Cambridge: The MIT Press, 2005, p.30.

6 Cf. SHOEMAKER, S. Functionalism and Qualia. Synthese, 27, 1975, p.291 - 315; KIRK, R. 'Why there couldn't be zombies'. Proceedings of the Aristotelian Society, Supplementary Volume, 1999, 73, pp.1-16; GÜZELDERE, G. 'The Many Faces of Consciousness: A Field Guide'. In: BLOCK, N. \& FLANAGAN, O. \& GÜZELDERE, G. The Nature of Consciousness. Massachusetts: MIT Press, 1999, pp. 1-68. 
com este serão considerados como mostrando que o argumento dos zumbis vai além do "problema das outras mentes" e cria o que chamei de "o problema da minha mente".

Para mostrar que o problema da minha mente surge diretamente do argumento dos zumbis desenvolvi uma série de intuitions pumps por considerar, assim como Dennett, que argumentos rigorosos servem para tratar problemas bem definidos, mas não servem para tratar algo que sequer há consenso se existe ou não, muito menos consenso sobre o que seria. Uma primeira intuition pump já tinha sido mostrada por Smullyan em seu pequeno artigo An Unfortunate Dualist. ${ }^{7}$ Nele somos levados a pensar em uma droga que aniquile nossa mente, mas mantenha o funcionamento do corpo, ou seja, uma droga que nos transforme em um zumbi. O problema é que se esta droga fosse administrada em alguém sem o conhecimento deste, tal desafortunado dualista nada perceberia e seguiria sua vida como se nada tivesse acontecido. Como o funcionamento dele é idêntico com ou sem qualia, ele nunca pararia para pensar que ele não mais percebe cores, sons, odores, sensações, sentimentos etc. A vida continuaria na sua naturalidade de sempre. Dito isto, podemos pensar em um teletransporte que copie as características físicas de alguém e as transfira para o mundo zumbi de Chalmers. Uma pessoa que fizesse esta viagem não notaria que perdeu suas qualia, e um zumbi que viesse para o nosso mundo não notaria que as adquiriu. Se fosse feita uma troca entre os dois sem que eles soubessem, eles continuariam suas vidas normalmente. Isto é um pressuposto natural do próprio argumento dos zumbis, o motivo principal para isso é que um zumbi, por mais que tente, é incapaz de descobrir que é um zumbi. Mas, então, eu posso ser um zumbi e ser incapaz de descobrir que sou! Para deixar isto mais intuitivo, podemos imaginar que nosso mundo está em uma constante alternância entre estados de zumbis e estados "normais". Se este fosse o caso, pelo próprio argumento dos zumbis não seríamos capazes de descobrir quando somos zumbis e quando não somos. Por isso, um verdadeiro conhecedor do argumento dos zumbis, se entrasse em um fictício contato com seu irmão gêmeo zumbi, teria que eventualmente admitir que não tem certeza se é ele ou seu irmão que é consciente. Este, então, é o problema que chamei de problema da minha mente, se zumbis são possíveis posso ser um e não saber.

O problema da minha mente nos mostra que o argumento dos zumbis bane as qualia para fora de todo e qualquer contato, se elas existem, existem de um modo onde elas só podem influenciar a si mesmas e nada mais.

7 Cf. SMUlLYAN, R. M. 'An Unfortunate Dualist'. In: HOFSTADTER, D.R. \& DENNETT, D.C. The Mind's I, New York: Basic Books, 1981, pp.383-384. 
Por isso se as perdêssemos não notaríamos falta de nada. São o que Wittgenstein chamaria de roda que gira sem girar nenhuma outra roda, tal roda pode ser removida sem que a máquina note. É aqui que surge o problema para o dualismo, as qualia deveriam ser aquilo que temos de mais íntimo e imediato. Com o argumento dos zumbis aquilo que deveria ser o mais próximo se tornou o mais distante. Além disso, tal argumento se baseia na diferença entre humanos e zumbis, se não podemos pensar nesta diferença não podemos dar sentido ao argumento. Mas se não podemos ter certeza de que não somos zumbis como podemos saber que estamos imaginando uma diferença entre nós e eles? Por isso consideramos que o argumento dos zumbis, ao contrário de ser um argumento a favor do dualismo, é um argumento contra o dualismo. É este próprio argumento que nos mostra que, se tais propriedades extras e não físicas do nosso mundo existissem, não poderíamos ter certeza se elas existem ou não. Isto é um golpe mortal se, além de tudo, tais propriedades forem consideradas como aquilo que temos de mais certo.

Chalmers percebe este problema e tenta respondê-lo no capítulo sobre o paradoxo do julgamento fenomenal e em seu artigo "the content and epistemology of phenomenal belief" ${ }^{8} \mathrm{O}$ próprio Chalmers considera tal problema "the greatest tension that a nonreductive theory is faced with". ${ }^{9}$ Mais especificamente, este é o que ele chama primeiro tipo de argumento, ou melhor, desafio, derivado da questão do auto-conhecimento quando aplicada ao problema dos zumbis. Resumindo tal argumento, ele diz: "if my judgments are formed by the same mechanisms as a zombie's, they cannot be any more justified" ${ }^{10}$ Tendo admitido o problema, ele passa para a sua resolução. Após uma breve apresentação da resposta de Chalmers, pretendo mostrar não só que tal resposta é ineficaz, como também que os argumentos que foram apresentados aqui são facilmente confundidos com este primeiro tipo de argumento do modo que foi apresentado por ele, no entanto, não são o mesmo argumento.

Chalmers admite que um pressuposto natural do argumento dos zumbis é que a consciência é irrelevante para a explicação que damos para nossos julgamentos sobre a consciência. O motivo é que o mundo físico deve ser causalmente fechado para que zumbis físicos sejam logicamente possíveis. É deste ponto que surge o chamado paradoxo do julgamento fenomenal. Em suas próprias palavras:

8 CHALMERS, D. The Content and Epistemology of Phenomenal Belief. IN: SMITH. Q. \& JOKIC, A. Consciousness: New Philosophical Perspectives. Oxford: Oxford University Press, 2003. Agradeço ao próprio Chalmers por ter sugerido este artigo após ter lido o artigo que lhe mandei.

9 CHALMERS, 1996, op. cit., p.181.

10 CHALMERS, ibidem, p. 193. 
The paradox is a consequence of the facts that (1) the physical domain is causally closed; (2) judgments about consciousness are logically supervenient on the physical; (3) consciousness is not logically supervenient on the physical; and (4) we know we are conscious. From premise (1) and (2) it follows that judgments about consciousness can be reductively explained. In combination with premise (3), this implies that consciousness is explanatory irrelevant to our judgments, which lies in tension with premise (4). Thus we have the paradox. ${ }^{11}$

O paradoxo está, assim, exposto pelo seu próprio criador, se a consciência é irrelevante para o nosso julgamento sobre a consciência, como sabemos que somos conscientes? Para Chalmers, a resposta é simples: a consciência é um fato inegável, somos conscientes de ser conscientes, por isso não temos motivos algum para duvidar de nossa consciência. Deste modo, ao invés de tentar resolver o paradoxo, ele propõe simplesmente que "the trick is to learn to live with the combination". ${ }^{12}$ Ou seja, não podemos por em dúvida nossa consciência, sabemos que o fechamento causal do mundo físico é, provavelmente, um fato e descobrimos, através do argumento dos zumbis, que a consciência não é física, então, já que temos certeza destas premissas, devemos simplesmente aprender a aceitar o paradoxo que vem com elas. O ponto principal aqui é que a consciência é, para Chalmers, um bruto explanandum, ${ }^{13}$ ela é um fato que não pode ser negado, então qualquer argumento que chegue à conclusão de que ela não existe está, por princípio, errado. O fato de que somos conscientes é algo evidente que não pode ser negado, por isso não interessa se ela é irrelevante ou não. Tentar negá-la seria não levá-la a sério. Levar a consciência a sério é algo que Chalmers assume desde o começo de seu livro, significa aceitar a sua evidência imediata, o que nos proíbe de negar a sua existência. Esta é uma crítica muito comum que ele faz a seus opositores, ele normalmente os acusa de não levarem a consciência a sério ou, em outras palavras, de ignorarem o Problema Difícil. Além disso, de nada adiantaria falar que um zumbi também defenderia que ele mesmo é consciente exatamente da mesma maneira que Chalmers defende, pois isto só significaria que o comportamento dos dois é idêntico, mas isto não significa que, no que diz respeito à consciência, os dois também sejam idênticos. Ou seja, eles podem ser idênticos de um ponto de vista de terceira pessoa, mas não são idênticos de um ponto de vista de primeira pessoa. Eu posso duvidar que Chalmers seja consciente, mas ele não pode duvidar que ele é consciente. Embora ele e seu zumbi se comportem de maneiras iguais, ele sabe que não é um zumbi

11 CHALMERS, ibidem, p. 183.

12 CHALMERS, ibidem, p.184.

13 CHALMERS, ibidem, p.188. 
porque tem evidência disso, a saber, a sua própria consciência. A consciência seria uma espécie de prova de si mesma. Nas palavras de Chalmers: "This may sound somewhat paradoxical at first, but really it is simply saying the obvious: our experience of consciousness enables us to know that we are conscious". ${ }^{14}$

Em poucas linhas, a resposta dele é baseada na premissa de que não posso duvidar da minha própria consciência, isto seria não levar a consciência a sério, o que é descartado logo no começo do livro. A consciência seria um dado indubitável, uma evidência imediata, por isso, embora você não possa saber se eu sou um zumbi ou não, eu sei que não sou e sei que estou certo, pois tenho consciência de ter consciência. Ou seja, a consciência seria prova de si mesma. Tendo este dado como dado indubitável, simplesmente teríamos que aprender a viver com o fato de que o meu comportamento não é influenciado pela minha consciência, mesmo quando diz respeito a julgamentos ou crenças sobre a minha própria consciência. Mesmo que a consciência não tenha nenhum papel a representar, eu simplesmente estou certo quando digo que sou consciente e o zumbi simplesmente está errado. Isto pode ser contraintuitivo, mas teríamos bons argumentos para aceitar tal posição. Nas palavras de Chalmers, teríamos que "learn to live with". ${ }^{15}$ Podemos, então, identificar quatro modos principais que ele usou para responder a tal paradoxo que, embora estejam todos intimamente ligados, serão tratados separadamente aqui, a saber, o fato de que a consciência é um explanandum que não pode ser negado, o fato de que devemos leva-la a sério, o fato de que devemos aprender a viver com tal paradoxo e, por último, o fato de que a consciência é prova de si mesma. Tratemos, então, cada questão desta separadamente.

O problema mais evidente de todos com as respostas de Chalmers é que ele diz que praticamente qualquer pessoa que não tenha uma visão sobre a consciência parecida com a que ele defende, que esta pessoa não está levando a consciência a sério. Esta é a crítica mais comum que ele faz e, logo no começo do livro, ele diz que este livro só deveria ser lido por quem leva a consciência a sério. Em primeiro lugar, temos que levar em consideração que levar a consciência a sério tem dois sentidos que são aqui confundidos. O primeiro sentido é mais abrangente, significa simplesmente estudar de maneira séria o problema da consciência. O segundo é mais específico, significa defender um conceito de consciência parecido com o que Chalmers defende. O problema é que Chalmers confunde estes dois sentidos, para ele uma pessoa só está estudando de maneira séria o proble-

14 CHALMERS, ibidem, p.199.

15 CHALMERS, ibidem, p.288. 
ma da consciência se defende um conceito de consciência parecido com o dele. Por isso levar a sério significa, para ele, pressupor um certo conceito de consciência. Excluindo o fato de que os outros filósofos, com certeza, consideram que estão levando a consciência a sério, temos ainda o problema de que, quando Chalmers diz isso, ele praticamente já fez todo o trabalho que deveria fazer. Uma vez dito o que é levar a consciência a sério, a teoria dele simplesmente flui sem grandes problemas. Prova disso é que o próprio Chalmers diz no começo de seu livro que "the real argument of the book is that if one takes consciousness seriously, the position I lay out is where one should end up" ${ }^{16}$ Mas a questão é que o verdadeiro problema da consciência é justamente "o que é levar a consciência a sério?" Ou melhor, "como devemos levá-la a sério?" Como fazer isso é o problema, e não pode ser pressuposto ou assumido. Se você começa a sua teoria já pressupondo um certo conceito de consciência e negando todos os outros, pois eles não a levam a sério, você já fez tudo o que deveria fazer. Uma vez colocado o coelho na cartola, ou a moeda atrás do arbusto, é fácil tirá-lo de lá. Quem quer realmente levar a consciência a sério, no sentido abrangente, deve entender que o conceito de consciência proposto por Chalmers é justamente o que está em questão, o fato de que deste conceito podemos chegar à existência de zumbis e ao dualismo naturalista é secundário. Por isso, quando Chalmers diz que alguém não está levando a consciência a sério, devemos simplesmente entender que este alguém não aceita o conceito de consciência que Chalmers defende. Tendo isto em vista, fica claro que esta resposta não o ajuda em nada, ele simplesmente está dizendo para alguém que não concorda com o seu conceito de consciência que este alguém não concorda com o seu conceito de consciência. Ou seja, não está dizendo nada.

No entanto, por considerar o seu conceito o único conceito que trata de maneira séria o problema da consciência, Chalmers nos diz que se tal conceito nos levar a um paradoxo, teríamos que simplesmente aprender a conviver com ele. Para ele, sua teoria, ou variantes parecidas com ela, seriam as únicas possíveis para quem decide levar a consciência a sério. Por isso teríamos que simplesmente aprender a viver com o fato de que esta teoria nos leva ao que o próprio Chalmers chamou de "The Paradox of Phenomenal Judgment". Teríamos argumentos fortes o suficiente para aceitar tal teoria, mesmo levando em consideração as teses extremamente contraintuitivas a que elas nos levariam no que diz respeito aos nossos julgamentos sobre nossos estados conscientes. O problema aqui é que as teses que Chalmers defende giram ao redor, principalmente, da possibilidade lógica de existi-

16 CHALMERS, ibidem, p.XIII. 
rem zumbis. Se zumbis não forem concebíveis, nada mais resta. No entanto, foi a própria possibilidade lógica de existirem zumbis que nos levou ao que o próprio Chalmers chamou de "the paradox of phenomenal judgment". Mas, se uma tese nos leva a um paradoxo, deveríamos, para dizer o mínimo, suspeitar que tal tese não deva ser logicamente possível. Paradoxos estão longe de ser consequências naturais de argumentos logicamente possíveis. Chalmers frequentemente diz que não vê problema algum em conceber zumbis, que eles são perfeitamente concebíveis e que não temos motivos para pensar o contrário. Mas o fato de que tal paradoxo é uma consequência natural dos argumentos dele deveria ser o suficiente para indagarmos se realmente estamos concebendo algo quando concebemos um zumbi. Se realmente estamos levando em conta todas as implicações que seguem naturalmente da conceptibilidade de um zumbi. Simplesmente aprender a viver com o paradoxo está longe de ser um movimento aceitável.

Não obstante, Chalmers também diria que um movimento muito menos aceitável e muito mais paradoxal seria negar um dado indubitável. Ele considera a consciência um dado indubitável, uma evidência imediata. Deste modo, eu sei que sou consciente, estou certo e ponto final. Você pode duvidar do fato de que eu sou consciente, mas eu, sendo consciente, não posso duvidar da minha própria consciência. Não teríamos absolutamente motivo algum para duvidar de nossa consciência. Devo ressaltar aqui que é no mínimo interessante observar o fato de que alguém possa acreditar que algo é um dado imediato e indubitável, mesmo sabendo que outras pessoas dizem que tal dado simplesmente não existe. Se ele é indubitável isto, por princípio, não deveria acontecer. Esta é, com certeza, uma das motivações que vai levar Chalmers a dizer que estas pessoas simplesmente não levam a consciência a sério, o que já foi mostrado que é um erro. Mas o mais interessante ainda é que podemos encontrar no próprio Dennett o argumento dos zumbis de Chalmers, mas com uma conclusão final diferente. Em seu livro, Consciousness Explained, de 1991, Dennett nos fala de um zumbi que seria "em princípio" indistinguível do homem, mas seria um verdadeiro zumbi. Para ele, dizer que zumbis poderiam ser em princípio indistinguíveis do ser humano, ou seja, dizer que zumbis físicos são logicamente possíveis, seria dizer que "genuine consciousness is epiphenomenal in the ridiculous sense. That is just silly". ${ }^{17}$ Podemos perceber, então, que Dennett, de certa forma, aceitou o argumento dos zumbis. Se zumbis físicos são possíveis a consciência é um epifenômeno. Isto é surpreendente, pois temos aqui o principal crítico dos zumbis despercebidamente aceitando o

17 DENNETT, D. Consciousness Explained. Boston: Little, Brown and Company, 1991, p.405. 
argumento dos zumbis como um todo, 5 anos antes de Chalmers ter escrito seu livro! Só que, para Dennett, tal epifenomenalismo é simplesmente ridículo e inaceitável, pois a consciência não teria papel causal nenhum a representar e não poderia ter surgido dentro da evolução biológica. Como tal teoria não deve ser levada a sério, zumbis físicos não são possíveis. Assim, Dennett nos mostra que o argumento de Chalmers pode ser compreendido na mesma direção, mas em sentido oposto. ${ }^{18}$ Como se fosse exatamente o mesmo argumento, mas lido de trás para frente. Chalmers parte de um certo conceito de consciência para provar um certo tipo de dualismo de propriedades, já Dennett parte da negação de tal dualismo para chegar na negação deste conceito de consciência. O mesmo argumento está sendo usado, mas em sentido oposto. Mais importante aqui do que defender quem está certo é perceber que não existe uma resposta óbvia e que, portanto, a outra não poderia ser, por princípio, negada. Deste modo, o que é chamado de óbvio e indubitável, não é tão óbvio assim e de maneira nenhuma é indubitável. Esta constatação já deveria bastar para mostrar que argumentos que apelam para obviedade não são aceitáveis.

Contudo, o problema aqui não é este. A questão é que há sim um motivo para se duvidar que a consciência exista e este motivo é justamente o argumento dos zumbis! A criatura se volta contra o seu criador, pois, se zumbis são possíveis, como posso ter certeza de que não sou um? A única coisa que poderia me dar certeza de que não sou um zumbi são estes tais estados qualitativos que não influenciam em nada o julgamento que tenho sobre mim mesmo. Ou seja, para eu ter certeza de que não sou um zumbi devo ter meu julgamento sobre mim mesmo influenciado por algo que, por princípio, não pode influenciar meu julgamento. Se pudesse, zumbis não seriam possíveis, pois não poderiam fazer julgamentos sobre si mesmos como nós fazemos, lhes faltaria algo.

É o próprio argumento dos zumbis que nos leva a questionar nossas qualia. Como Chalmers pode saber se quando ele escreveu o seu livro ele não era um zumbi? Como pode saber se estados conscientes e estados de zumbis não se alternam a cada 5 minutos? Como pode saber se ele não é um zumbi agora? Pelo seu próprio argumento sabemos que o fato dele achar que é consciente não prova que ele seja. A resposta que ele daria para isso seria sempre a mesma, a saber, ele diria que sabe que não é um zumbi porque está consciente de ser consciente e, mesmo sabendo que seu zumbi diria exatamente a mesma coisa, Chalmers simplesmente estaria certo e seu zumbi estaria errado. A consciência é prova de si mesma, para si mesma.

18 Tal problema foi melhor desenvolvido em um outro artigo: LEAL-TOLEDO, G. Dennett e Chalmers: Argumento e Intuição. Trans/Form/Ação, 2(29). p. 123-132. 2006. 
Chegamos ao último problema. A consciência teria um estatuto especial, ela seria inquestionável, pois, no caso dela, ter justifica crer que tenho. Se tenho consciência não posso duvidar que tenho. Acabamos de mostra que isso não é bem assim, se a consciência fosse realmente indubitável, então estaria provado que ela não existe, já que o próprio Chalmers admite que muitos duvidam de sua existência. Isto causa tamanha perplexidade em Chalmers que tudo o que lhe resta é dizer que "to this, all I can say is that Dennett's introspection is very different from mine". ${ }^{19}$ Afinal de contas, Dennett está fazendo algo que Chalmers considera impossível, talvez ele seja um zumbi! No entanto, o problema que está sendo levantado agora não é este, a questão é que mesmo se a consciência for prova de si, ou seja, mesmo se Chalmers estiver certo, eu ainda posso ser um zumbi e não saber. O motivo é que, por sua própria teoria, a consciência não faz diferença nenhuma no que diz respeito sobre os julgamentos sobre a consciência. Um zumbi e um ser humano fariam os mesmo julgamentos, só que um estaria errado e o outro estaria certo.

A consciência seria prova de si. Mas que prova é essa que não faz diferença nenhuma no julgamento que faço sobre mim mesmo? De que me adianta que a minha consciência esteja certa de si se isto em nada pode alterar como eu julgo a mim mesmo? A consciência pode estar certa de si, mas eu posso não estar certo dela. Em outras palavras, mesmo que aceitemos que a consciência é prova de si mesma, ela ainda não pode me auxiliar em nada para que eu prove a mim mesmo que eu não sou um zumbi. Ela está certa de si, mas eu não estou certo dela. Ou seja, eu ainda posso ser um zumbi e não saber. O próprio Chalmers admite que "beliefs about experiences lie at a distance from experience" ${ }^{20} \mathrm{O}$ que, segundo ele mesmo, faz com que exista a possibilidade de corrigir nossas crenças sobre nossas experiências. Eu posso estar errado em meus julgamentos sobre a minha experiência. Nas palavras de Chalmers: "although direct phenomenal beliefs are incorrigible, subjects are not incorrigible about whether they are having a direct phenomenal belief" ${ }^{21}$ Independente do detalhe do que é uma "direct phenomenal belief", deve-se levar em consideração aqui o fato de que há uma distância entre a consciência ser consciência-de-si-mesma e a consciência ser a consciência-de-alguém, de uma pessoa. É a pessoa que faz julgamentos sobre si, é ela que diz se é ou não um zumbi, de nada adianta que ela tenha uma propriedade especial incorrigível se tal propriedade não pode influenciar diretamente os julgamentos que ela faz sobre si mesma.

19 CHALMERS, 1996, op. cit. p.189.

20 CHALMERS, ibidem, p. 197.

21 CHALMERS, 2003, op. cit. 
Mais uma vez está sendo mostrado que, com argumento dos zumbis, as qualia são banidas para um mundo paralelo onde elas até podem estar certas de si, mas em nada isso nos auxilia para que mostremos a nós mesmos que não somos zumbis. O fato defendido por Chalmers de que a consciência é sempre certa de si em nada nos ajuda, até porque consciências não duvidam, são pessoas, sujeitos, que duvidam e são estes é que podem duvidar se são ou não zumbis.

O estranho é que Chalmers parece acreditar ter um acesso as qualia mais direto do que simplesmente acreditar que tem qualia. Seria um acesso pré-teórico, fora da cognição, um acesso imediato. Mas o problema com este tipo de acesso é que não dá para fazer teoria e realmente achar que se está falando dele. Tal tipo especial de acesso, se existisse, não nos permitiria falar sobre ele. Fora da cognição significa fora da cognição! O que nos leva de volta ao ponto original, se está fora da cognição não pode nos auxiliar no nosso julgamento sobre nós mesmos, então podemos ser zumbis e não saber.

Para tentar resolver este problema, ele defende que a experiência é uma parte constitutiva da crença na experiência. De algum modo a minha experiência de ver vermelho seria uma parte constitutiva da minha crença de que vejo vermelho. Poderíamos assim, conhecer nossas qualia, pois as qualia fariam parte do próprio conhecimento que temos sobre elas. Nas palavras de Chalmers "the connection between experience and phenomenal belief is tighter than any causal connection: it is constitution" ${ }^{22}$ Uma primeira questão a ser levantada aqui é o que significa conhecer no caso das qualia. Se este tipo de conhecimento é tão diferente do tipo comum de conhecimento, o que ainda me permite chamá-lo de conhecimento? Se não é conhecimento, é o que? Mas, além disso, sempre que necessito de algo para conhecer este algo tenho um famoso problema, a saber, como identificar algo que já pressuponho na identificação? Qual é o critério? Tal problema da falta de critério foi tratado por Wittgenstein como podemos ver nas seguintes citações: ${ }^{23}$

258. Let us imagine the following case. I want to keep a diary about the recurrence of a certain sensation. To this end I associate it with the sign ' $S$ ' and write this sign in a calendar for every day on which I have the sensation. - I will remark first of all that a definition of the sign cannot be formulated. - But still I can give myself a kind of ostensive definition. - How? Can I point to the sensation? Not in the ordinary sense. But I speak, or write the sign down, and at the same time I concentrate my

22 CHALMERS, ibidem.

23 Agradeço a Daniel Dennett e Camila Jourdan por terem notado as semelhanças entre os argumentos aqui defendidos e os argumentos de Wittgenstein. 
attention on the sensation - and so, as it were, point to it inwardly. - But what is this ceremony for? For that is all it seems to be! A definition surely serves to establish the meaning of a sign. - Well, that is done precisely by the concentrating of my attention; for in this way I impress on myself the connexion between the sign and the sensation. - But 'I impress it on myself' can only mean: this process brings it about that I remember the connexion right in the future. But in the present case I have no criterion of correctness. One would like to say: whatever is going to seem right to me is right. And that only means that here we can't talk about 'right'.

Ou ainda:

213. (...) If intuition is an inner voice. - How do I know how to obey it? And how do I know that it doesn't mislead me? For if it can guide me right, it can also guide me wrong. $^{24}$

Não teria a capacidade filosófica de explicar ou defender o argumento da linguagem privada de Wittgenstein, no entanto, tais citações mostram um problema que nos interessa aqui. Se o vermelho é parte constitutiva do meu julgamento sobre o vermelho, fico completamente incapaz de descobrir se tal experiência que chamo hoje de vermelho é a mesma que chamei ontem! Perco completamente o critério, já que se um lado muda o outro muda junto. Para poder perceber tal mudança eu deveria como que 'gravar' a experiência de vermelho que constitui meu julgamento sobre o vermelho de modo que, se a minha experiência mudasse, eu poderia compará-la com a experiência que está 'gravada' em meu julgamento. Mas, a experiência que constitui o meu julgamento sobre minhas experiências e as experiências que são o objeto do meu julgamento são uma e a mesma experiência. Isto quer dizer que se uma muda a outra muda também, assim sempre estarão 'combinando', nunca poderei notar a mudança. Além disso, se eu pudesse notar a mudança, nunca seria capaz de dizer qual lado mudou: foi a experiência que estava 'gravada' e que constitui o meu julgamento sobre como é ver vermelho que mudou ou foi a própria experiência de ver vermelho? ${ }^{25}$ Como disse Wittgenstein: "se ela pode me conduzir corretamente, também pode me enganar". Mais uma vez voltamos ao ponto original, mesmo se Chalmers estiver certo ao dizer que as crenças dos zumbis sobre suas qualia são constitutivamente diferentes das nossas porque as deles são vazias, ainda assim, se não podemos notar a mudança, poderíamos perder todas as nossas experiências e não notaríamos nada. As duas crenças podem

\footnotetext{
24 WITTGENSTEIN, L. Investigações Filosóficas. São Paulo: Nova Cultural, 1989. (Os Pensadores)

25 Podemos ver um argumento semelhante em DENNETT, D.C. Quining Qualia. In: CHALMERS, D. Philosophy of Mind: classical and contemporary readings. Nex York: Oxford University Press, 2002. pp. 226-246.
} 
ser constitutivamente diferentes, mas ainda assim representam o mesmo papel no que diz respeito ao julgamento que faço sobre mim mesmo. Aquilo que as constituiu é incapaz de mudar meus julgamentos. Ainda posso ser um zumbi e não saber. Resumindo da maneira mais clara possível: para saber se sou um zumbi ou não devo fazer um julgamento sobre mim mesmo. No entanto o próprio argumento dos zumbis nos mostra que a nossa consciência não influencia o julgamento que fazemos sobre nós mesmos. Isto quer dizer que sou incapaz de descobrir se sou um zumbi ou não.

É importante notar que, se o que foi dito está correto, mesmo se a teoria de Chalmers for verdadeira, mesmo se realmente existir uma diferença entre zumbis e seres humanos, todos os problemas levantados ainda surgiriam. Do ponto de vista dos próprios seres humanos, eles não seriam capazes de descobrir se são zumbis ou não. Só um desconhecido ser, de alguma maneira superior aos seres humanos e aos zumbis, de modo que tenha um inusitado acesso externo aos nossos estados qualitativos intrínsecos, seria capaz de dizer quem é quem. Surge, aqui, a diferença entre o que foi defendido neste artigo e o que foi defendido por Shoemaker em Functionalism and Qualia $^{26}$ e, posteriormente criticado por Chalmers em seu livro. O problema aqui não é o modo como nossos julgamentos são produzidos e nem mesmo se nossas crenças são idênticas às dos zumbis, pois mesmo se elas fossem diferentes, é uma diferença sem critério de diferença. Aquilo que poderia diferenciar nossas crenças das dos zumbis não influencia em nada o julgamento que fazemos sobre nós mesmos, não influencia nossas crenças.

Deste modo o argumento dos zumbis sabota sua própria estrutura. Neste argumento as qualia, que eram justamente aquele último refúgio indubitável de todo dualista onde o materialismo encontraria uma barreira difícil de transpor, passam a ser colocadas em dúvida. O dualismo acaba por se voltar contra si mesmo. Assim, justamente esta tentativa de levar a consciência a sério separando-a de tudo o que ela não é, nos levou na direção oposta da que era pretendida. É como se tivéssemos retirado de uma caixa tudo o que não era consciência, mas, quando olhamos dentro da caixa, para ver a consciência, não tinha mais nada lá dentro.

LEAL-TOLEDO, Gustavo. Chalmers' paradox. Trans/Form/Ação, São Paulo, v.32(2), 2009, p.159-173.

- ABSTRACT: The Zombie Argument proposed by Chalmers, instead of working as a defense of dualism, banishes qualia to a 'world' where they cannot influence

26 Cf. SHOEMAKER, S. Functionalism and Qualia. Synthese, 27, 1975, p.291-315. 
our judgments about ourselves. For this reason, according to the argument itself, we may be all zombies and not know it. This is what Chalmers called The Paradox of Phenomenal Judgment. The problem is that he accepts this paradox as part of his theory. This philosophical move, however, is not acceptable, for the paradox undermines Chalmers' theory, by showing that the zombie argument is, actually, an argument against dualism. Chalmers tries to solve this problem with many arguments based on the status of consciousness as brute indubitable explanandum. However, this attempt is a failure by a series of reasons showing that, even if he were right, we could still be zombies and not know it.

- KEYWORDS: David Chalmers, Daniel Dennett, Zombies, Qualia, Dualism.

\section{Referências bibliográficas}

CHALmeRS, D. H. The Conscious Mind. Oxford: Oxford University Press, 1996.

The Content and Epistemology of Phenomenal Belief. IN: SMITH. Q. \& JOKIC, A. Consciousness: New Philosophical Perspectives. Oxford: Oxford University Press, 2003.

DENNETT, D. Consciousness Explained. Boston: Little, Brown and Company, 1991.

"The Unimagined Preposterousness of Zombies: Commentary on Moody, Flanagan, and Polger". In: Journal of Consciousness Studies, n. 2, v.4, 1995b, pp. 322-28.

Quining Qualia. In: CHALMERS, D. Philosophy of Mind: classical and contemporary readings. Nex York: Oxford University Press, 2002. pp. 226-246.

Sweet Dreams. Cambridge: The MIT Press, 2005.

GÜZELDERE, G. 'The Many Faces of Consciousness: A Field Guide'. In: BLOCK, N. \& FLANAGAN, O. \& GÜZELDERE, G. The Nature of Consciousness. Massachusetts: MIT Press, 1999, pp. 1-68.

JOURDAN, C. O Fim das Explicações. Como uma regra se liga com suas aplicações: o problema da 'determinação infinita' na filosofia do segundo Wittgensetein. 2005 Dissertação (Mestrado em Filosofia) - Departamento de Filosofia, Pontifícia Universidade Católica do Rio de Janeiro. Rio de Janeiro, 2005.

KIRK, R. 'Zombies vs materialists'. In: Aristotelian Society Supplement, 48, 1974, pp. 135-52.

'Why there couldn't be zombies'. Proceedings of the Aristotelian Society, Supplementary Volume, 1999, 73, pp. 1-16.

LEAL-TOLEDO, G. O Argumento dos Zumbis na Filosofia da Mente: são zumbis físicos logicamente possíveis? 2005. Dissertação (Mestrado em Filosofia) - Departamento de Filosofia, Pontifícia Universidade Católica do Rio de Janeiro, Rio de Janeiro, 2005.

Dennett e Chalmers: Argumento e Intuição. In: Trans/Form/Ação, 2(29), 2006, pp. 123-132. 
LEAL-TOLEDO, G. \& TEIXEIRA, J. de F. Dualism and the Zombie Argument in $20^{\text {th }}$ Century Philosophy of Mind. In: Análise, II, 2, 2005, pp. 35-52.

NAGEL, T. 'Conceiving The Impossible and the Mind-Body Problem'. Philosophy, 1998, 73, 285, pp. 337-352.

POLGER, T. W. 'Zombies Explained'. In: ROSS, D. \& BROOK, A. \& THOMPSON, D. (eds) Dennett's Philosophy: A Comprehensive Assessment. Massachusetts: MIT Press, 2000, pp. 259-286.

SHOEMAKER, S. Functionalism and Qualia. Synthese, 27, 1975, p. 291-315.

SMULLYAN, R. M. 'An Unfortunate Dualist'. In: HOFSTADTER, D. R. \& DENNETT, D. C. The Mind's I. New York: Basic Books, 1981, pp. 383-384.

WITTGENSTEIN, L. Investigações Filosóficas. São Paulo: Nova Cultural, 1989. (Os Pensadores) 